\title{
The mud flat anemone-cockle association: mutualism in the intertidal zone?
}

Received: 29 October 2002 / Accepted: 12 January 2003 / Published online: 1 February 2003

(C) Springer-Verlag 2003

\begin{abstract}
The intertidal cockle Austrovenus stutchburyi exists in a symbiotic relationship with the mud flat anemone Anthopleura aureoradiata, the latter using the shell of buried cockles as the only available hard substrate for attachment. The cockles are also host to a detrimental larval trematode Curtuteria australis that invades the bivalves through the filtration current, and here we demonstrate that the anemones significantly depress the rate by which cockles accumulate parasites in the field. Along the tidal gradient, the relative parasite load of cockles was lowest where anemones were most abundant, and the area occupied by anemones per square meter sediment surface explained $30 \%$ of the spatial variation in infection intensity. At a smaller spatial scale, parasite loads were significantly lower $(34 \%)$ in cockles from patches with than without anemones at the same tidal height. A field experiment manipulating the density of anemones showed that the rate of parasite accumulation in cockles decreased with increasing anemone density, and that the generally positive relationship between infection intensity and cockle size tended to disappear in the presence of anemones. The results suggest that the anemone-cockle symbiosis is a non-obligate mutualistic relationship in which the former is provided with a suitable substrate for attachment whereas the latter obtains protection against parasitic infections.
\end{abstract}

Keywords Anthopleura aureoradiata $\cdot$ Austrovenus stutchburyi · Parasite avoidance - Tidal gradient . Trematode infection

\section{Introduction}

In recent years, ecologists and epidemiologists have joined forces to better understand the impact and spread of parasites and diseases in wild animal populations (see Hudson et al. 2002). Our current knowledge of the

K. N. Mouritsen $(\bullet) \cdot$ R. Poulin

Department of Zoology, University of Otago,

P.O. Box 56, Dunedin, New Zealand transmission dynamics of parasites, however, is based mainly on simple models or experimental systems in which the hosts and parasites are considered in an ecological vacuum. In reality, hosts are integral parts of diverse communities, and other species in the community, although not used as hosts by a parasite, can nevertheless influence its transmission success and therefore the infection rates of host species. There is a need to incorporate these non-host organisms and their impact on host-parasite population dynamics into communitylevel frameworks, in order to assess the true impact of parasites and diseases on host populations and on the communities of which they are part.

One of the many ways in which non-host organisms can affect host-parasite interactions involves predation on the parasite's dispersal or infective stages. Many helminth and arthropod parasites produce free-living larval stages, which serve as agents of infection: if their numbers are reduced by predation or other means, rates of host infection will decrease. For instance, all trematode parasites use first intermediate hosts, usually snails, in which they multiply asexually to produce free-swimming, infective larvae known as cercariae that encyst in the trematode's second intermediate host (Kearn 1998). In the laboratory, several non-host organisms, ranging from rotifers to fish, have been shown capable of preying on trematode infective stages, or of preventing them from infecting their hosts in other ways (e.g., Bunnag et al. 1977; Anderson et al. 1978; Rajasekariah 1978; Christensen 1979; Christensen et al. 1980; Stirewalt and Lewis 1981; Fernandez et al. 1991). Whether the action of the non-host organisms actually has measurable effects on parasite transmission in the field remains unknown in most cases, however. Here, we provide field evidence that a non-host organism can influence infection rates in the second intermediate host of a trematode, and argue that this phenomenon is responsible for spatial and interindividual differences in infection risk among hosts.

The cockle Austrovenus stutchburyi (Veneridae) is the dominant bivalve of sheltered soft-sediment shores in New Zealand (Morton and Miller 1973). In many places, 
its shell represents the only hard substrate where various benthic invertebrates can establish. In fact, some of these invertebrates are found almost exclusively on live cockle shells, forming a very distinctive assemblage (Morton and Miller 1973). One of these species is the small mud flat anemone Anthopleura aureoradiata (Anthozoa: Actiniidae). Individual cockles can harbour several anemones, although there is much spatial variation both between adjacent cockles and between different tidal heights of the intertidal zone. Cockles are also second intermediate hosts of the trematode Curtuteria australis (Digenea: Echinostomatidae). Cercariae, produced asexually and in large numbers inside a whelk first intermediate host, invade a cockle through the inhalant siphon and encyst as metacercariae in the cockle's foot (Allison 1979). The parasite's life cycle is completed when an infected cockle is ingested by the definitive host, the oystercatcher Haematopus ostralegus. Heavily-parasitised cockles are unable to burrow properly $1-2 \mathrm{~cm}$ under the sediment surface as lightly- or uninfected cockles do, because of the debilitating effect of the metacercariae in their foot (Thomas and Poulin 1998; Mouritsen 2002). This leads to a significant increase in the risk of avian predation faced by heavily-infected cockles (Thomas and Poulin 1998), as well as a greater risk of non-lethal predation by footcropping fish (Mouritsen and Poulin 2002). Cockles therefore incur an important fitness cost following infection by this trematode, roughly proportional to the number of metacercariae they accumulate.

The general question we address here is: can anemones prey on trematode cercariae before they infect cockles, thus reducing the actual exposure of cockles to the parasite? Given the size of particles on which the anemones can feed, this is a very likely possibility. At the scale of the individual cockle, anemones might intercept cercariae as they approach the siphon of the cockle on which they are attached. On a larger spatial scale, the water above an area of high anemone density might be cleared of cercariae, providing a reduced infection rate for all cockles settled in the area, whether or not they harbour anemones. In this study, we investigate the effect of anemones on trematode accumulation by cockles, at different spatial scales, using both field experiments and comparisons of cockle infection levels between individuals or areas. To our knowledge, this is the first quantitative attempt to demonstrate that a nonhost organism can influence parasite transmission rates in the field.

\section{Materials and methods}

The study was carried out during the austral autumn 2002 on the tidal flats of Company Bay and Gills Corner, Otago Harbour, South Island, New Zealand. The sheltered muddy sand flat of Company Bay supports a large population of anemones with a well-defined zonation, and the resident cockles are usually found heavily infected by larval Curtuteria australis. The tidal flat at Gills Corner, in contrast, is a semi-exposed sand flat characterised be the presence of very few anemones and moderate to high intensity of $C$. australis infections in the local cockle population.
Field collections

At Company Bay, animals were collected in February at 13 stations separated by $6 \mathrm{~m}$ along a tidal gradient from the spring low tide mark to the upper mid intertidal zone. At each station, six core samples $\left(0.012 \mathrm{~m}^{2}\right)$ were taken and the number of cockles and attached anemones were recorded. A random sub-sample of 24-30 cockles per station was returned to the laboratory, where the cockle length, the basal disk-diameter of each attached anemone, and the distance from the attachment site of each anemone to the posterior margin of the cockle shell were measured. The latter measure was included to clarify whether the anemones' position in relation to the inhalant siphon affects the accumulation of parasites. The cockles were then dissected and their feet were removed and pressed between two slides followed by the enumeration under a stereomicroscope of metacercarial cysts of $C$. australis, clearly visible through the transparent foot tissue. Because cockles in Otago Harbour are subject to foot-cropping by benthic-feeding fish that significantly reduce the number of Curtuteria cysts found in their foot (Mouritsen and Poulin 2002), cropped cockles were excluded from the analysis. This reduced the sample size regarding infection intensities to 12-25 individuals per station.

Besides a significant tidal zonation (see Results), the anemones also show considerable small-scale horizontal heterogeneity in densities. To elucidate whether this small-scale anemone patchiness is reflected in the infection intensity of cockles, 26 pairs of similarly sized cockles were collected at station 6 (see Fig. 1). Each pair consisted of a cockle harbouring two to four anemones from a patch with a high anemone density, and a cockle without anemones from a patch without anemones. Individuals from each pair were separated by less than $1 \mathrm{~m}$. The animals were brought to the laboratory and the number of $C$. australis cysts in each cockle was determined as above.

\section{Field experiment}

In order to investigate the effect of different anemone densities on the rate at which larval $C$. australis accumulate in cockles, a field experiment was carried out at Gills Corner. This location was chosen as the experimental site due to the absence of significant numbers of anemones and the relatively high abundance of parasites. Forty-five plastic-mesh cages were placed $1 \mathrm{~m}$ apart along a straight line parallel to the water line at the lower mid intertidal level. The cages were cylindical $(14 \mathrm{~cm}$ high, $8 \mathrm{~cm}$ in diameter) with a mesh size of $16 \times 20 \mathrm{~mm}$. Each cage was pushed $9 \mathrm{~cm}$ into the sediment, leaving $5 \mathrm{~cm}$ above the substrate, and the sediment inside was cleared of local cockles. Two cockles originating from Company Bay and one experimental cockle originating from the Otakou sand flat (also in Otago Harbour) were then placed in each cage. The Company Bay cockles were used as an easy source of anemones, whereas the Otakou cockles, which do not support a population of anemones, were chosen as the experimental individuals due to their low level of Curtuteria infection. By transplanting these lightly infected cockles to Gills Corner, the infection intensity of experimental cockles was expected to build up and depart from pre-experimental levels relatively quickly (see Mouritsen 2002). Dissecting an additional 15 cockles from Otakou assessed pre-experimental infection levels. Three treatments (15 replicates each) were systematically alternated along the line of cages: (1) no anemones attached to either of the cockles, (2) three anemones attached to each of the three enclosed cockles, (3) six anemones attached to each of the three cockles, resulting in an enclosed initial anemone density in the three treatments corresponding to zero, 1,800 and 3,600 individuals $\mathrm{m}^{-2}$, respectively. The number of attached anemones was manipulated either by removing excess animals (Company Bay cockles) or allowing detached anemones to re-attach by leaving cockles and anemones together in outdoor water-tanks for a few days (Otakou cockles). After establishment, all cages were closed at the top (same mesh type) and left for 12 weeks after which the number of anemones in each cage was recorded and the enclosed Otakou- 

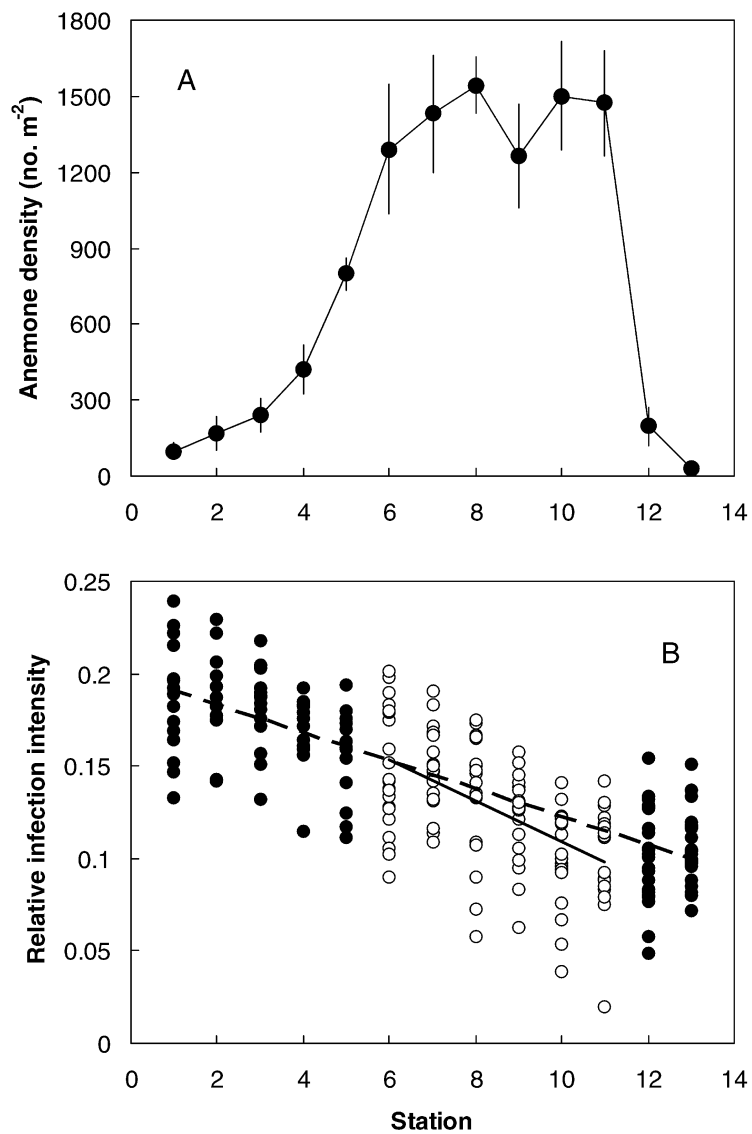

Fig. 1. A The mean density of anemones Anthopleura aureoradiata (no. $\mathrm{m}^{-2} \pm \mathrm{SE}$ ) as a function of decreasing tidal height. B The relative infection intensity of cockles Austrovenus stutchburyi (lntransformed no. metacercariae per mm cockle) as a function of decreasing tidal height. The broken and solid lines represent the regression lines for data from stations supporting a relatively low $\left(O ; F_{1,123}=306.62, P<0.0005\right)$ and relatively high $\left(O ; F_{1,123}=55.90\right.$, $P<0.0005)$ anemone density, respectively. Station 1 and 13 represents the upper mid-intertidal and the spring low tide level, respectively

cockles were returned to the laboratory for dissection. The experimental cockles were of approximately similar size (shell length $28.8-33.1 \mathrm{~mm}$ ) and mean $( \pm \mathrm{SD})$ disk diameter (at the base) of the attached anemones was $6.8 \pm 1.9 \mathrm{~mm}(n=185)$. The latter figure corresponds well to the mean anemone diameter found at the 13 transect-stations in Company Bay (4.4-7.9 mm).

\section{Data analysis}

The data analysis was carried out in SPSS and all tests were preceded by formal evaluation of assumptions. Because the parasite load of cockles generally increases with size in a non-linear manner, infection intensities are analysed and presented as lntransformed and size (shell length)-corrected values, i.e. relative infection intensity, unless otherwise stated. The residual analyses are based on unstandardised residuals obtained from a linear regression between relative infection intensity and tidal height, except in the case of the relationship between relative infection intensity and anemone area at the level of the cockle individual. Here, values are standardised residuals from intensity-size regressions carried out station by station.

\section{Results}

Anemone and parasite distribution in Company Bay

The anemones show a well-defined pattern of intertidal zonation with densities peaking between station 6 and 11 (Fig. 1A). The mean anemone size in terms of disk base area was more or less stable from stations 1-10 (around $30 \mathrm{~mm}^{2}$ ) but then increased to a maximum of $54 \mathrm{~mm}^{2}$ at station 13. This means that the mean area occupied by anemones per $\mathrm{m}^{2}$ resembles well the density pattern by peaking between station $6\left(368 \mathrm{~cm}^{2} \mathrm{~m}^{-2}\right)$ and $11\left(498 \mathrm{~cm}^{2}\right.$ $\mathrm{m}^{-2}$ ). In contrast, the infection intensity by Curtuteria australis in the cockles appeared to decrease steadily with decreasing tidal height (Fig. 1B). However, an analysis of the data divided into two groups according to the abundance of anemones (high abundance: stations 6-11; low abundance: stations $1-5$ and 12-13), shows for both groups significant negative linear regressions between infection intensity and decreasing tidal height, but also a significantly greater negative slope in the high abundance group than in the low abundance group (ANCOVA, $F_{1,246}=5.86, P=0.016$; Fig. $1 \mathrm{~B}$ ). This demonstrates that the infection intensity of cockles decreases more rapidly as a function of tidal height when anemones are abundant in order to reach a local minimum where the total anemone area $\mathrm{m}^{-2}$ peaks. Here, the back-transformed infection intensity is $48 \%$ lower than expected from the interpolated regression line (see Fig. 1B). In support, based on infection intensity residuals correcting for the effect of tidal height, the mean infection intensity of cockles was significantly lower in the tidal zone with the most anemones (stations 6-11) than that of cockles from the remaining transect (Student's $t$-test, $t_{248}=2.29, P=0.023$ ). Also based on residuals across the entire transect, the mean infection intensity per station was negatively related to the area occupied by the anemones, the latter accounting for $30 \%$ of the variation in parasite loads among stations (Fig. 2). The regression was, however, only marginally significant $\left(r^{2}=0.30, F_{1,12}=4.68, P=0.053\right)$.

In addition to the vertical relationships, the infection intensity of $C$. australis in cockles was also affected by small-scale horizontal variation in anemone density: at the same tidal height, the average parasite load was significantly lower (34\%) in cockles originating from patches of high anemone density (and with anemones attached to the shell) than in cockles from nearby patches without anemones (Fig. 3, Paired $t$-test, $t_{25}=3.35$, $P=0.003$ ).

Focusing on the level of the individual cockle, however, no negative relationship between infection intensity and the number (or area) of attached anemones could be demonstrated across all cockles from the transect. In fact, based on standardised residuals (obtained station by station) there was a significant positive relationship between parasite load and the total area of attached anemones (Fig. $4, r^{2}=0.036, d f=248, P=0.002$ ). Similar results were obtained also regarding the total number of anemones, and for both the number and area of 


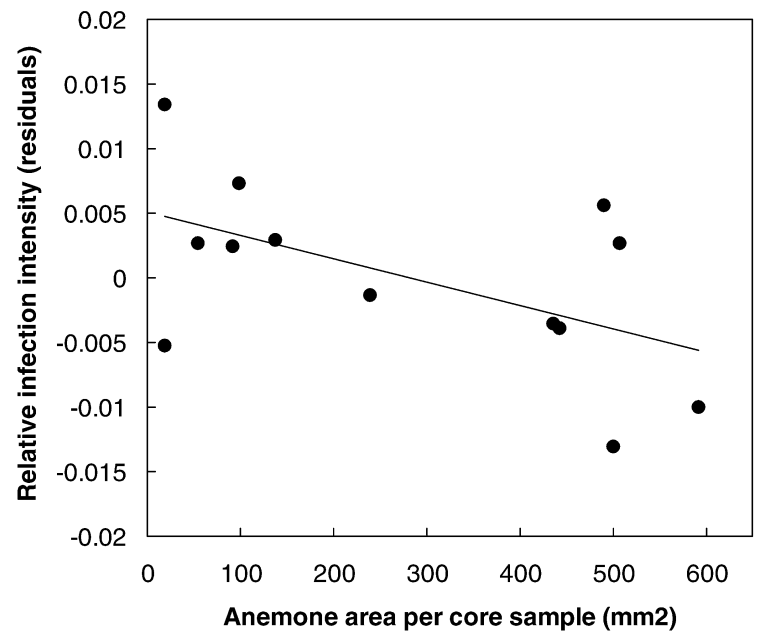

Fig. 2 The mean relative infection intensity of cockles Austrovenus stutchburyi (unstandardised transect residuals) as a function of the mean area occupied by anemones Anthopleura aureoradiata per core sample at the 13 investigated stations

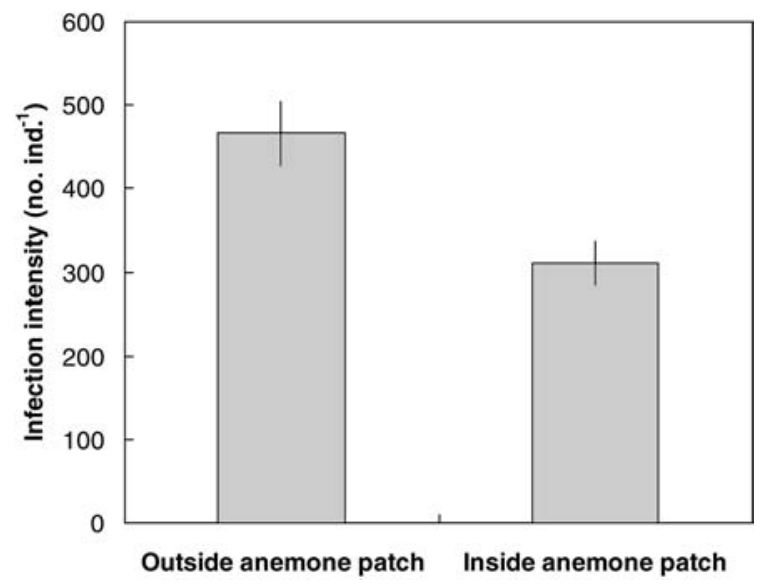

Fig. 3 The mean infection intensity of cockles Austrovenus stutchburyi (no. metacercariae per individual $\pm \mathrm{SE}$ ) originating from the same tidal height but retrieved from adjacent sites within and outside patches of the anemone Anthopleura aureoradiata $(n=26)$

anemones present in a distance of less than $12 \mathrm{~mm}$ and less than $6 \mathrm{~mm}$ from the posterior shell margin (the approximate siphon position), albeit $r^{2}$ - and $P$-values became increasingly smaller and greater, respectively, and eventually non-significant (data not shown). However, in lieu of the very low $r^{2}$-values it may be appropriate to consider the parasite load of individual cockles largely unaffected by the abundance and distribution of anemones on their own shell.

The mean cockle length increased linearly with decreasing tidal height, attaining a minimum of $27.6 \mathrm{~mm}$ and a maximum of $39.3 \mathrm{~mm}$ at the upper and lower station, respectively $\left(r^{2}=0.962, F_{1,12}=278.7, P<0.0005\right)$. Based on station-corrected size residuals, no significant relationship could be demonstrated between cockle size

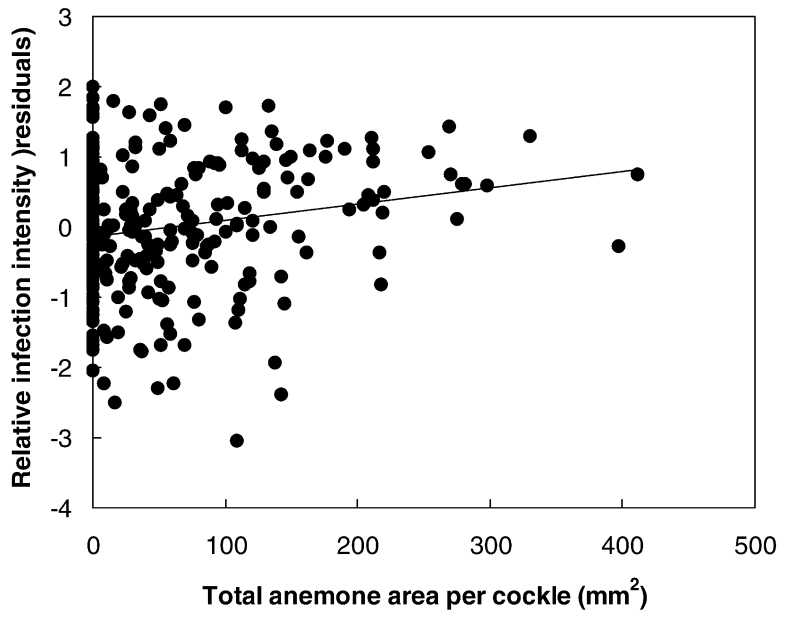

Fig. 4 The relative infection intensity of cockles Austrovenus stutchburyi (standardised station-by-station residuals) as a function of the total area of anemones attached to the shell $(n=250)$

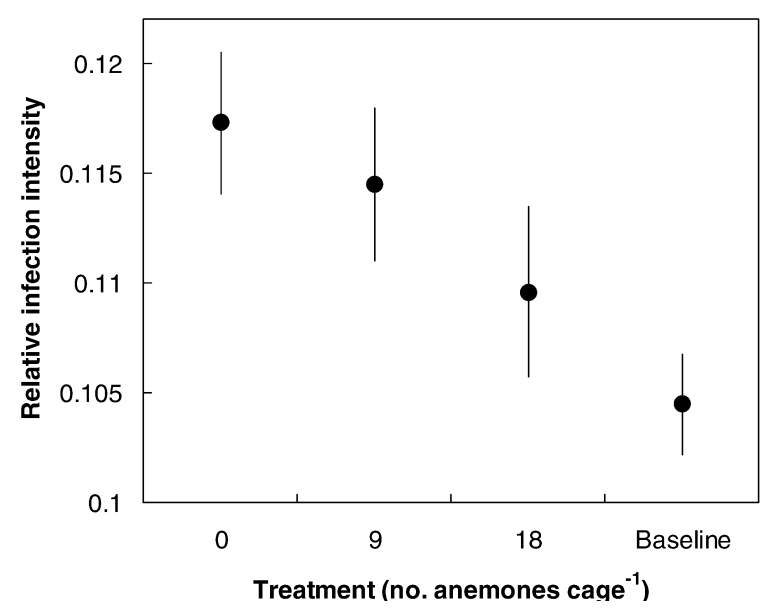

Fig. 5 The mean relative infection intensity of experimental cockles Austrovenus stutchburyi (ln-transformed no. metacercariae per $\mathrm{mm}$ cockle $\pm \mathrm{SE}$ ) caged with different initial numbers of anemones Anthopleura aureoradiata $(0,9$ or 18$)$ during the 12week field experiment. Baseline represents the mean pre-experimental parasite load. $n=15$ for all values

(and hence growth rate) and the mean anemone area per core sample $\left(r^{2}<0.0005, F_{1,12}=0.0035, P=0.95\right)$. This shows that the cockles' growth rate is unaffected by the presence of sea anemones, strongly suggesting that the latter have no serious negative impact on the former.

The field experiment

The mean parasite load in experimental cockles decreased with increasing number of anemones enclosed in the cages (Fig. 5). Including the pre-experimental infection intensity (baseline, see Fig. 5) as a group, there was a significant effect of treatment on the number of larval $C$. 


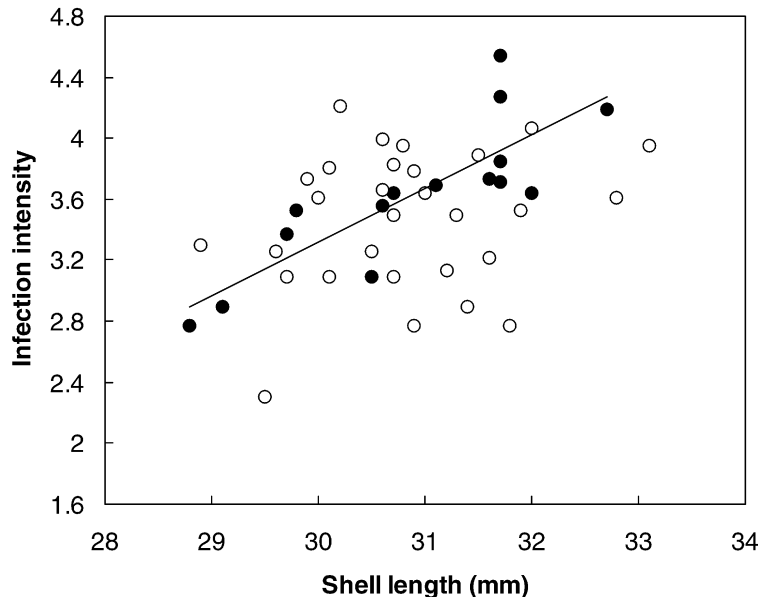

Fig. 6 The ln-transformed infection intensity (no. metacercariae per individual) as a function of shell length in cockles from the treatment without anemones $\left(\mathbf{O} ; r^{2}=0.68, F_{1,13}=28.15, P<0.0005\right)$, and in cockles from the 9- and 18-anemone treatment combined $\left(O ; r^{2}=0.06, F_{1,28}=1.77, P=0.19\right)$. Only the significant regression line is depicted

australis the cockles had accumulated during the experiment (one-way ANOVA, $F_{3,56}=2.97, P=0.039$ ). Bonferroni post hoc tests correcting for multiple comparison indicated that the mean parasite load of cockles in the treatment without anemones was significantly greater than the pre-experimental level $(P=0.024)$, whereas the parasite load of cockles from the two anemone treatments did not depart significantly from the baseline intensity $(P=0.11$ and 0.82 for 9 and 18 anemones per cage, respectively). This demonstrates that the anemones effectively depress the rate at which the larval trematodes accumulate in cockles, seemingly in a density-dependent manner. Based on back-transformed infection intensities, the rate of trematode accumulation was in the 18anemone treatment reduced by $23 \%$ in comparison to the treatment without anemones.

A considerable number of anemones (about 50\%) were lost during the experiment. Using the average anemone densities at the start and at the end of the experiment, the 9 and 18 anemone-treatment hence supported an effective density of about 1,300 and 2,500 individuals $\mathrm{m}^{-2}$, respectively. These figures correspond well to the 1,900-2,300 anemones $\mathrm{m}^{-2}$ found in high-density areas (based on individual core sample values) between stations 6 and 11 on the Company Bay transect, indicating that experimental densities simulated realistic field conditions.

The impact of the anemones also depended on cockle size. Whereas the infection intensity in cockles from the treatment without anemones was significantly and positively related to cockle size, no such relationship could be demonstrated among cockles from the two anemone treatments considered either separately or together (Fig. 6). A positive relationship between parasite load and size is generally found in samples of cockles, evident also in the baseline cockles $(r=0.70, d f=14, P=0.004)$.

\section{Discussion}

Through several lines of evidence at different spatial scales, the present study demonstrates that mud flat anemones significantly depress the rate at which larval Curtuteria australis accumulate in cockles. At the level of the intertidal flat, the lowest relative parasite loads were found among cockles from tidal heights where anemones were most abundant, and at a given tidal height, the infection intensity was lower at sites where anemones were present than at nearby sites where they were absent. The field experiment demonstrated that the observed negative relationships between infection intensity and anemone abundance are a direct consequence of the anemones' presence rather than due to another yet unidentified factor or process that happens to correlate positively with anemone density. Regarding the transect data, one such factor could be the distribution of infected first intermediate hosts, but dissections of several hundred mud whelks from Company Bay have revealed no Curtuteria infections, and it is believed that the present larval trematodes originate from areas outside the bay, brought there by tidal currents.

Given that most sea anemones, including Anthopleura spp., are non-selective feeders preying on a wide spectrum of food items ranging in size from minor detritus particles and planktonic organisms to larger molluscs and fish (Shepherd and Gray 1986; Chintiroglou and Koukouras 1992; Acuna and Zamponi 1995; Kruger and Griffiths 1996, 1998; personal observation), the mechanism by which the mud flat anemones depress the cockles' rate of parasite accumulation is most likely through direct predation of swimming cercariae (having a body length of about $2 \mathrm{~mm}$ ) during their transmission from whelks to cockles. Echinostome cercariae typically express a geopositive and/or photonegative behaviour, causing them to swim close to the sediment surface (e.g. Allison 1979; Montaudouin et al. 1998). Considering the substantial area often covered by the anemones, a considerable proportion of the cercariae released from the snail host can hence be envisaged to fall prey to anemones before they successfully manage to invade a second intermediate host. Another potential mechanism may be mechanical disturbance of the cockle's siphons by anemone tentacles. If this occurs frequently, it will tend to depress an affected cockle's average filtration rate and thereby also parasite accumulation. However, such interactions may be relevant only at the highest anemone densities, and will tend to involve mainly the larger cockles that also possess the largest siphons. The lack of significant positive relationship between infection intensity and cockle size among anemone-bearing cockles from the field experiment (Fig. 6) could in part be explained by such interactions. Under average conditions, however, siphon disturbance may be of minor importance in comparison to direct predation of swimming parasites, as it would affect also the cockles' growth rate negatively; we found no evidence of this in the available data. 
The lack of negative relationship between infection intensity and the number/area of anemones attached at the level of the individual cockle (Fig. 4), suggests that the anemones generally do not prey on the trematode larvae at the point of entry through the cockle's inhalant siphon. When filtrating, the inhalant siphon protrudes from the posterior shell margin and the cockle therefore pumps in mainly the water positioned behind it. Since the average relative position of anemones on the cockle shell is 0.38 ( $\mathrm{SD}=0.17, n=651 ; 0$ and 1 corresponds to the posterior and anterior shell margin, respectively), contact between incoming cercariae and the attached anemones may be unlikely. So, the way by which the anemones depress the parasite load of the coexisting cockles seems mostly to be through diminishing the pool of larval parasites available at a spatial scale larger than the individual cockle. The field experiment does however demonstrate that the relevant spatial scale can indeed be very small.

The typical aggregation of parasites among their hosts is generally believed to result either from heterogeneity in the dispersal of infective stages, or intrinsic variability among individual hosts in their susceptibility to infection (Anderson and Gordon 1982; Wilson et al. 2002). The present findings demonstrate that a non-host organism can also influence parasite acquisition and contribute to parasite aggregation.

Our results also shed a new light on the symbiosis between anemones and cockles. Instead of anemones being merely commensals attached to cockles without affecting them, the two organisms may be involved in a non-obligate mutualistic relationship. Anemones obtain an attachment substrate from cockles, whereas cockles might benefit from a reduced rate of infection in exchange for harbouring anemones. A similar association between anemones and hermit crabs sharing the same shell is known to provide reciprocal benefits to both participants, because they mutually provide one another with protection against predators (e.g., Brooks 1988). However, this is the first report of an anemone protecting the animal to which it is attached against parasitic infection. Along with a documented symbiosis between various freshwater snails and an oligochaete (Chaetogaster limnaei) living in their mantle cavity (Khalil 1961; Wajdi 1964; Fashuyi and Williams 1977; Patzig and Schmid 1981), the anemone-cockle association is a rare example of a cleaning symbiosis (see Poulin and Grutter 1996; Côté 2000) in which the cleaning organism feeds on the parasites before and not after they infect the host.

There is another aspect to this mutualistic association. Anemones may benefit directly by lowering the infection rates to which their cockle hosts are exposed. Once cockles have accumulated high numbers of metacercariae and hence are incapable of reburying if exposed, their shell becomes an unsuitable attachment substrate for anemones as the latter face desiccation on the surfaced cockle (Thomas et al. 1998). Therefore, anemones benefit by keeping their cockle host burrowed via the ingestion of cockle parasites.
Acknowledgements The work was financially supported by the Marsden Fund, The Danish Natural Science Research Council (K.N.M), and via a James Cook Research Fellowship from the Royal Society of New Zealand (R.P.). We also wish to thank the referees for useful comments on an earlier draft.

\section{References}

Acuna FH, Zamponi MO (1995) Feeding ecology of intertidal sea anemones (Cnidaria, Actiniaria): food sources and trophic parameters. Biociencias 3:73-84

Allison FR (1979) Life cycle of Curtuteria australis n. sp. (Digenea: Echinostomatidae: Himasthlinae), intestinal parasite of the South Island pied oystercatcher. NZ J Zool 6:13-20

Anderson RM, Gordon DM (1982) Processes influencing the distribution of parasite numbers within host populations with special emphasis on parasite-induced host mortalities. Parasitology 85:373-398

Anderson RM, Whitfield PJ, Dobson AP, Keymer AE (1978) Concomitant predation and infection processes: an experimental study. J Anim Ecol 47:891-911

Brooks WR (1988) The influence of the location and abundance of the sea anemone Calliactis tricolor (Le Sueur) in protecting hermit crabs from octopus predators. J Exp Mar Biol Ecol 116:15-21

Bunnag T, Rabelo de Freitas J, Scott HG (1977) The predatory activity of Lebistes reticulatus (Peters, 1859) on Schistosoma mansoni miracidia in laboratory experiments. Trop Geogr Med $29: 411-414$

Chintiroglou C, Koukouras A (1992) The feeding habits of three Mediterranean sea anemone species, Anemonia viridis (Forskaal), Actinia equina (Linnaeus) and Cereus pedunculatus (Pennant). Helgol Wiss Meeresunters 46:53-68

Christensen NO (1979) Schistosoma mansoni: interference with cercarial host-finding by various aquatic organisms. J Helminthol 53:7-14

Christensen NO, Frandsen F, Nansen P (1980) The interaction of some environmental factors influencing Schistosoma mansoni cercarial host-finding. J Helminthol 54:203-205

Côté IM (2000) Evolution and ecology of cleaning symbioses in the sea. Oceanogr Mar Biol 38:311-355

Fashuyi SA, Williams MO (1977) The role of Chaetogaster limnaei in the dynamics of trematode transmission in natural populations of freshwater snails. Z Parasitenkd 54:55-60

Fernandez J, Goater TM, Esch GW (1991) Population dynamics of Chaetogaster limnaei limnaei (Oligochaeta) as affected by a trematode parasite in Helisoma anceps (Gastropoda). Am Midl Nat 125:195-205

Hudson PJ, Rizzoli A, Grenfell BT, Heesterbeek H, Dobson AP (2002) The ecology of wildlife diseases. Oxford University Press, Oxford

Khalil LF (1961) On the capture and destruction of miracidia by Chaetogaster limnaei (Oligochaeta). J. Helminthol 35:269-274

Kearn GC (1998) Parasitism and the platyhelminths. Chapman and Hall, London

Kruger LM, Griffiths CL (1996) Sources of nutrition in intertidal sea anemones from the south-western Cape, South Africa. S Afr J Zool 31:110-119

Kruger LM, Griffiths CL (1998) Sea anemones as secondary consumers on rocky shores in the south-western Cape, South Africa. J Nat Hist 32:629-644

Montaudouin X de, Wegeberg AM, Jensen KT, Sauriau PG (1998) Infection characteristics of Himasthla elongata cercariae in cockles as a function of water current. Dis Aquat Org 34:63-70

Morton J, Miller M (1973) The New Zealand sea shore, 2nd edn. Collins, London

Mouritsen KN (2002) The parasite-induced surfacing behaviour in the cockle Austrovenus stutchburyi: a test of an alternative hypothesis and identification of potential mechanisms. Parasitology 124:521-528 
Mouritsen KN, Poulin R (2002) The risk of being at the top: footcropping in the New Zealand cockle Austrovenus stutchburyi. J Mar Biol Assoc UK (in press)

Patzig F, Schmid K (1981) Chaetogaster limnaei K.E. v. Baer. Ein Problem in der Labor-wasserschneckenzucht für die Trematodenforschung. Z Parasitenkd 65:261-270

Poulin R, Grutter AS (1996) Cleaning symbioses: proximate and adaptive explanations. BioScience 46:512-517

Rajasekariah GR (1978) Chaetogaster limnaei K. von Baer 1872 on Lymnaea tomentosa: ingestion of Fasciola hepatica cercariae. Experientia 34:1458-1459

Shepherd SA, Gray JD (1986) Food of the anemone Anthothoe albocincta at West Island, South Australia. Trans R Soc S Aust 110:191-192

Stirewalt M, Lewis FA (1981) Schistosoma mansoni: effect of rotifers on cercarial output, motility and infectivity. Int $\mathrm{J}$ Parasitol 11: 301-303
Thomas F, Poulin R (1998) Manipulation of a mollusc by a trophically transmitted parasite: convergent evolution or phylogenetic inheritance? Parasitology 116:431-436

Thomas F, Renaud F, de Meeûs T, Poulin R (1998) Manipulation of host behaviour by parasites: ecosystem engineering in the intertidal zone? Proc R Soc Lond B 265:1091-1096

Wajdi N (1964) The predation of Schistosoma mansoni by the oligochaete annelid Chaetogaster. J Helminthol 38:391-392

Wilson K, Bjørnstad ON, Dobson AP, Merler S, Poglayen G, Randolph SE, Read AF, Skorping A (2002) Heterogeneities in macroparasite infections: patterns and processes. In: Hudson PJ, Rizzoli A, Grenfell BT, Heesterbeek H, Dobson AP (eds) The ecology of wildlife diseases. Oxford University Press, Oxford, pp 6-44 